Revta brasil. Bot., São Paulo,V.24, n.4 (suplemento), p.511-518, dez. 2001

\title{
Um novo conceito de monitoramento e comunicação ambiental: a rede européia para a avaliação da qualidade do ar usando plantas bioindicadoras (EuroBionet)
}

\author{
ANDREAS KLUMPP ${ }^{1,2}$, WOLFGANG ANSEL ${ }^{1}$, GABRIELE KLUMPP $^{1}$ e ANETTE FOMIN $^{1}$
}

(Recebido: 6 de setembro de 2000; aceito: 4 de abril de 2001)

\begin{abstract}
A new concept of environmental monitoring and communication: European network for the assessment of air quality by the use of bioindicator plants (EuroBionet)). In spite of all progress made in reducing the emission of air pollutants, the air quality is still unsatisfactory in many European cities. Bioindicator plants are of increasing importance for air quality control as their use makes it possible to prove and to demonstrate the negative impact of air pollutants on living organisms in a way that is easily comprehensible also to laymen. The pan-European project EuroBionet uses bioindicator plants to assess air pollution effects within a network of cities. Through a specific communication concept the scientific results of the project are translated and communicated in a way that addresses the public and raises environmental awareness. Thus the aim is to induce a change of attitude in parts of the urban population and to increase the acceptance of remedial measures. In the present paper the scientific and communicative aims and methods of the EuroBionet project are presented. First results of the exposure of tobacco plants in ten European cities during August and September 2000 show a gradient of increasing ozone impact from the North to the South and Centre of Europe with low injury degree in Scotland and Denmark and high degree in Italy, France, Austria and Southern Germany.
\end{abstract}

RESUMO - (Um novo conceito de monitoramento e comunicação ambiental: a rede européia para a avaliação da qualidade do ar usando plantas bioindicadoras (EuroBionet)). Apesar de todo o progresso alcançado na redução da emissão de poluentes atmosféricos durante as últimas décadas, a poluição do ar ainda representa um dos principais problemas ambientais nos centros urbanos da Europa. Plantas bioindicadoras têm um papel cada vez maior no controle da qualidade do ar, já que seu uso comprova e demonstra os efeitos negativos da poluição em seres vivos de uma maneira facilmente inteligível, inclusive para leigos. Em uma rede de municípios, o projeto pan-europeu EuroBionet utiliza plantas bioindicadoras para a avaliação de possíveis efeitos da poluição aérea. Através de um conceito de comunicação específico, os resultados científicos do projeto são traduzidos e divulgados de uma forma que chama a atenção do público em geral e que sensibiliza a população urbana. Desta forma, pretendese induzir a uma mudança no comportamento e aumentar a aceitação de medidas corretivas. No presente trabalho, os objetivos científicos e de comunicação do projeto EuroBionet são apresentados. Os primeiros resultados da exposição de plantas de tabaco em dez cidades européias, durante os meses de agosto e setembro de 2000, demonstram um gradiente de impacto de ozônio do norte para o sul e centro da Europa, com efeitos leves na Escócia e Dinamarca e fortes nas plantas expostas na Itália, França, Áustria e sul da Alemanha.

Key words - Air pollution, environmental monitoring, bioindicator plants, environmental communication

\section{Introdução}

De acordo com o relatório "Europe's Environment: The Second Assessment" da Agência Européia do Meio Ambiente, mais do que dois terços da população européia vivem em centros urbanos, e a influência das cidades se estende muito além dos limites dos municípios, causando impactos regionais e globais, devido ao

1. Universität Hohenheim, Institut für Landschafts- und Pflanzenökologie, 70593 Stuttgart, Alemanha.

2. Corresponding author: aklumpp@uni-hohenheim.de uso dos recursos naturais, da produção de lixo e das emissões de poluentes para o solo, a água e o ar (EEA 1998).

Apesar de todo o progresso alcançado na proteção do meio ambiente durante as últimas décadas, a poluição do ar ainda representa um dos principais problemas ambientais nos centros urbanos da Europa. Comparada com a situação de 40-50 anos atrás, a qualidade do ar tem mudado e melhorado significativamente na maioria das cidades, devido à redução de emissões e o desenvolvimento de tecnologias de ponta. A contribuição de gases ácidos como dióxido de enxofre e ácido fluorídrico tanto quanto de alguns metais pesados como, por exemplo chumbo, tem 
diminuído drasticamente. Hoje em dia, uma grande quantidade de diferentes poluentes ocorre em concentrações variáveis. As mais importantes fontes de poluentes atmosféricos são indústrias, usinas termoelétricas, incineradores de lixo, calefação doméstica e, especialmente, tráfego de automóveis. Emissões oriundas dos diversos meios de transporte têm uma crescente importância (EEA 1998). Entre os inúmeros poluentes emitidos para a atmosfera, em áreas urbanas, ou gerados por processos secundários, dióxido de enxofre, óxidos de nitrogênio, ozônio, materiais particulados e compostos orgânicos como benzeno ou hidro-carbonetos aromáticos policíclicos são os mais significativos. Particularmente, os compostos fotoquímicos (ozônio, por exemplo) e, em algumas regiões, também os materiais particulados, têm uma importância cada vez maior, devido ao aumento do tráfego de automóveis. Possíveis efeitos mutagênicos das complexas misturas de poluentes atmosféricos nas cidades têm recentemente causado preocupação pública.

Concentrações elevadas de poluentes atmosféricos representam um risco para a saúde humana, danificam flora e fauna e destroem monumentos históricos e construções modernas. Tais efeitos ocorrem com alta freqüência em aglomerações urbanas, considerando que uma grande quantidade dos mais diversos poluentes está sendo emitida em área relativamente limitada e muitos indivíduos estão sendo afetados, devido à alta densidade populacional.

A qualidade do ar pode ser avaliada, em nível local, regional, nacional e internacional, através de estimativas das emissões, do uso de modelos matemáticos e de medidas das concentrações ambientais dos principais poluentes usando métodos físico-químicos. Através de tais medidas, pode-se verificar se normas e valores limites para concentrações de poluentes no ar, estabelecidos ou recomendados por governos nacionais ou pela União Européia, estão sendo respeitados. Os resultados dessas medidas, porém, não permitem conclusões imediatas sobre os impactos das concentrações atuais de poluentes em seres vivos. $\mathrm{Na}$ verdade, os possíveis efeitos dependem não somente da concentração e da duração do impacto, mas também de muitos fatores diferentes como o clima, o estado nutricional, a predisposição, a idade, o impacto simultâneo de outros poluentes e outros que desempenham um papel importante (Arndt et al. 1995). Por isso, é essencial para a motivação da opinião pública, das repartições públicas e das empresas particulares que os efeitos negativos da poluição sejam amplamente estudados e demonstrados, para que medidas corretivas possam ser iniciadas e melhor aceitas pela população.

O uso de bioindicadores é a metodologia adequada para a detecção de efeitos de poluentes atmosféricos sobre organismos. A coleta sistemática de dados relativos a esses efeitos permite a criação de um inventário de respostas à poluição, o que representa o terceiro sistema de informação no controle da qualidade do ar, adicionalmente aos inventários de emissões e de concentrações ambientais. O emprego de bioindicadores, portanto, não pretende e não consegue substituir medições de concentrações ambientais de poluentes através de métodos físico-químicos, mas fornece informações adicionais referentes a efeitos sobre organismos vivos (Arndt et al. 1995, VDI 1999, Klumpp 2001). A padronização das técnicas, desde o cultivo e a exposição das plantas até a medição de efeitos e avaliação dos resultados, é um requisito fundamental para a validade e a aplicabilidade dos dados obtidos. Porém, a grande diversidade de métodos aplicados nos inúmeros estudos conduzidos e publicados em vários países europeus utilizando plantas como bioindicadoras da poluição do ar, não somente inviabiliza a comparação dos dados obtidos, mas também contribui para reduzir a aceitação desse método biológico de controle da qualidade do ar frente às autoridades e à opinião pública. Por esse motivo, vem sendo feito um esforço para a padronização de métodos de bioindicação, como, por exemplo, para uso de tabaco e couve, plantas indicadoras da presença de ozônio e hidrocarbonetos, respectivamente (VDI 1999, 2000), e para introduzir tais métodos padronizados em nível da União Européia, visando a sua unificação (Klumpp 2001).

Em consequência da situação descrita acima, foi criado, em 1999, o projeto "Rede européia para a avaliação da qualidade do ar usando plantas bioindicadoras (EuroBionet)", dentro do programa "LIFE Environment" da União Europeia (EC 1998). Sob a coordenação da Universidade de Hohenheim na Alemanha, os municípios e regiões de Edimburgo e Sheffield (Reino Unido), Copenhagen 
(Dinamarca), Düsseldorf (Alemanha), Grande Nancy e Grande Lyon (França), Klagenfurt (Áustria), Verona (Itália) e Catalunha/Barcelona (Espanha), mais a cidade de Ditzingen (Alemanha) como parceira associada, participam desta rede de biomonitoramento de qualidade do ar, a maior instalada em centros urbanos na Europa. O projeto tem duração prevista de três anos, sendo dois anos de exposição de plantas bioindicadoras e um ano para trabalhos preparatórios e avaliação final (EuroBionet 2000).

Seus objetivos científicos são: estabelecer o uso de plantas bioindicadoras para a avaliação da qualidade do ar em nível europeu utilizando métodos padronizados; transferir conhecimentos e métodos na área de bioindicação para instituições científicas e repartições públicas; criar um banco de dados relativos ao impacto de poluentes aéreos em áreas urbanas; analisar e avaliar a qualidade do ar; comparar os tipos de poluição presentes nas diferentes cidades e fornecer dados para medidas corretivas visando à redução das emissões de poluentes em nível local, regional, nacional e europeu.

Porém, entre políticos, administradores e pesquisadores, é cada vez mais aceito que o monitoramento da qualidade ambiental e a simples coleção de dados técnicos somente não são suficientes para alcançar um desenvolvimento sustentável dos grandes centros urbanos. Para que uma mudança no comportamento da população urbana possa ser induzida e que medidas corretivas como, por exemplo, um controle mais rígido do trânsito, sejam cada vez mais aceitas, os dados científicos e técnicos devem ser traduzidos e comunicados de uma forma que agrade ao público e aumente a preocupação para com o meio ambiente. Por isso, o projeto EuroBionet vai muito além de outros estudos de biomonitoramento desenvolvidos e implementados por instituições científicas e organizações governamentais e não governamentais. De uma maneira única, o projeto combina a avaliação da qualidade do ar, usando plantas bioindicadoras, parceria de municípios europeus de vários países e publicidade ("marketing"). Esse projeto pretende fazer a poluição ambiental visível e compreensível para as pessoas na vida cotidiana. Conseqüentemente, os seguintes objetivos podem ser destacados na área de comunicação: demonstrar ao público o impacto de poluentes atmosféricos em seres vivos; informar a população sobre a qualidade do ar na sua cidade; sensibilizar a população para com problemas ambientais; incentivar atividades dos próprios municípios, de escolas, grupos e indivíduos na área de proteção ambiental e melhoria da qualidade de vida e fornecer aos parceiros opções e possibilidades de utilizar a participação no projeto para o marketing municipal e como fator comercial.

\section{Material e métodos}

Biomonitoramento - Considerando a situação atual da poluição atmosférica nas grandes cidades européias, foram escolhidas cinco espécies de plantas bioindicadoras, incluindo indicadoras de reação, que respondem a poluentes definidos ou grupos de poluentes com danos visíveis ou alterações anatômicas, e indicadoras de acumulação que são relativamente resistentes à poluição aérea, mas acumulam substâncias tóxicas nos tecidos foliares permitindo a detecção do poluente através de análises químicas (figura 1). A tabela 1 contém um resumo dos métodos aplicados no presente projeto.

$\mathrm{O}$ uso de plantas bioindicadoras no monitoramento da qualidade do ar segue etapas definidas, as quais foram resumidas na figura 2. O cultivo, a exposição e as análises visuais e químicas das plantas são feitas de acordo com um manual interno de métodos elaborado pela equipe do projeto, que se baseia nas normas do VDI $(1978,1999,2000)$ e nos trabalhos de Arndt et al. (1985), Fomin et al. (1995) e Peichl (1997).

Em todas as cidades do EuroBionet, foram escolhidos 8 a 10 sítios de estudo, incluindo áreas controles, áreas urbanas e sub-urbanas e áreas com tráfego intenso. Em cada área, foram instalados equipamentos para a exposição das espécies bioindicadoras, conforme descrito em Arndt \& Schweizer (1991). À Universidade de Hohenheim cabe a coordenação geral e a organização dos trabalhos, enquanto as equipes locais

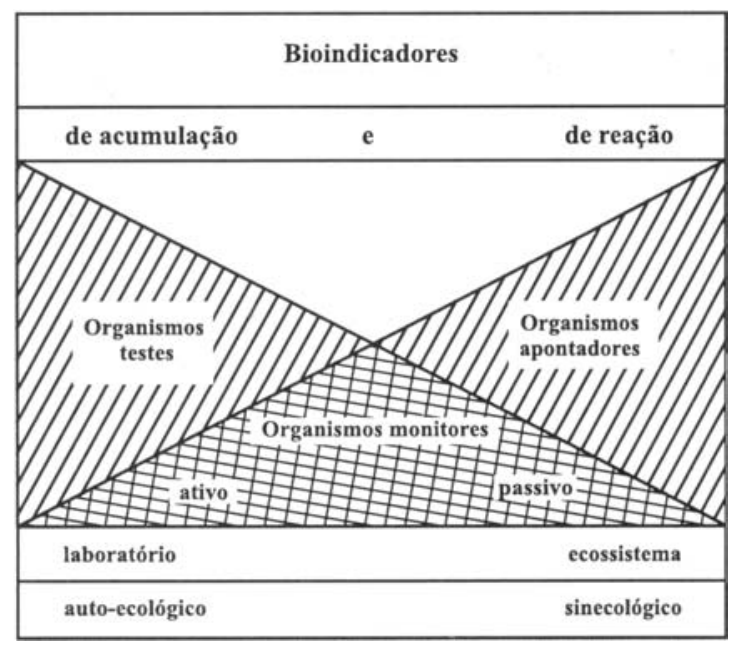

Figura 1. Esquema geral da designação de diferentes formas de uso de bioindicadores (modificado de Arndt et al. 1995). 
Tabela 1. Métodos de biomonitoramento empregados no projeto EuroBionet.

\begin{tabular}{|c|c|c|c|c|c|}
\hline $\begin{array}{c}\text { Espécie } \\
\text { indicadora }\end{array}$ & $\begin{array}{c}\text { Nome } \\
\text { científico }\end{array}$ & Poluente & $\begin{array}{c}\text { Parâmetro } \\
\text { estudado }\end{array}$ & $\begin{array}{l}\text { Tempo de } \\
\text { exposição }\end{array}$ & Referências \\
\hline Tabaco & $\begin{array}{c}\text { Nicotiana } \\
\text { tabacum cv. Bel- } \\
\text { W3 }\end{array}$ & Ozônio & Necrose foliar & 2 semanas & $\begin{array}{l}\text { Arndt et al. } \\
\text { (1985), } \\
\text { Heggestad } \\
\text { (1991) }\end{array}$ \\
\hline Choupo & $\begin{array}{l}\text { Populus nigra } \\
\text { (clone Brandaris) }\end{array}$ & Ozônio & $\begin{array}{l}\text { Necrose foliar, } \\
\text { crescimento, } \\
\text { perda de folhas }\end{array}$ & 14 semanas & Ballach (1997) \\
\hline Tradescantia & $\begin{array}{c}\text { Híbrido entre } \\
\text { Tradescantia } \\
\text { subcaulis e } T \text {. } \\
\text { hirsutifolia } \\
\text { (clone \# 4430) }\end{array}$ & $\begin{array}{l}\text { Substâncias } \\
\text { genotóxicas }\end{array}$ & $\begin{array}{l}\text { Mutações em } \\
\text { células-mãe de } \\
\text { grãos de pólen } \\
\text { (bioensaio } \\
\text { Trad-MCN) }\end{array}$ & 30 horas & $\begin{array}{c}\text { Ma et al. (1994) } \\
\text { Fomin et al. } \\
(1995)\end{array}$ \\
\hline $\begin{array}{c}\text { Cultura } \\
\text { padronizada de } \\
\text { gramíneas } \\
\text { (azevém) }\end{array}$ & $\begin{array}{c}\text { Lolium } \\
\text { multiflorum ssp. } \\
\text { italicum cv. } \\
\text { Lema }\end{array}$ & $\begin{array}{l}\text { Metais pesados } \\
(\mathrm{Cd}, \mathrm{Cr}, \mathrm{Cu}, \mathrm{Pb} \text {, } \\
\mathrm{Ni}, \mathrm{Zn}) \text {, } \\
\text { elementos-traço } \\
(\mathrm{Pt}, \mathrm{Sb}) \text {, enxofre }\end{array}$ & Acúmulo & 4 semanas & $\begin{array}{l}\text { VDI (1978), } \\
\text { Peichl (1997) }\end{array}$ \\
\hline Couve & $\begin{array}{l}\text { Brassica } \\
\text { oleracea } \\
\text { acephala }\end{array}$ & $\begin{array}{l}\text { Hidrocarbonetos } \\
\text { aromáticos } \\
\text { policíclicos }\end{array}$ & Acúmulo & 8 semanas & $\begin{array}{c}\text { Peichl (1997), } \\
\text { VDI (2000) }\end{array}$ \\
\hline
\end{tabular}

são os responsáveis pela execução do programa de biomonitoramento (tabela 2).

Comunicação-Um conceito novo de comunicação foi desenvolvido por uma empresa de comercialização de marcas e campanhas de publicidade. Os principais componentes desse conceito são:

- "Corporate identity". Criar um nome e um logo para o projeto que forneça uma marca, uma identidade comum a todos os participantes do projeto.

- Apresentar o projeto em todos os meios de comunicação incluindo revistas e jornais, periódicos científicos, painéis, folhetos e internet. Portanto, os objetivos e resultados científicos serão publicados em períodicos científicos, enquanto a população em geral será informada através da mídia. As páginas na Internet oferecerão dados e informações tanto para pesquisadores quanto para o cidadão comum.

- A "experiência local". Como a maioria das espécies usadas neste projeto não responde à poluição de modo a ser perceptível aos seres humanos, ou seja, não reage através de danos visíveis, surgiria um problema de comunicação. As pessoas não conseguiriam visualizar os efeitos nas plantas. Já que o objetivo principal do projeto é aumentar a preocupação das pessoas para com o meio ambiente e, finalmente, motivá-las a alterar o seu compartamento, o problema crucial do projeto reside no fato da "planta não se comunicar". A solução foi encontrada na instalação de um pavilhão EuroBionet em cada cidade, um cubo fechado que brinca com a curiosidade das pessoas (figura 3 ), onde são mantidas as plantas. Ele desperta interesse e curiosidade, da mesma maneira que a cerca de uma obra atrai a curiosidade

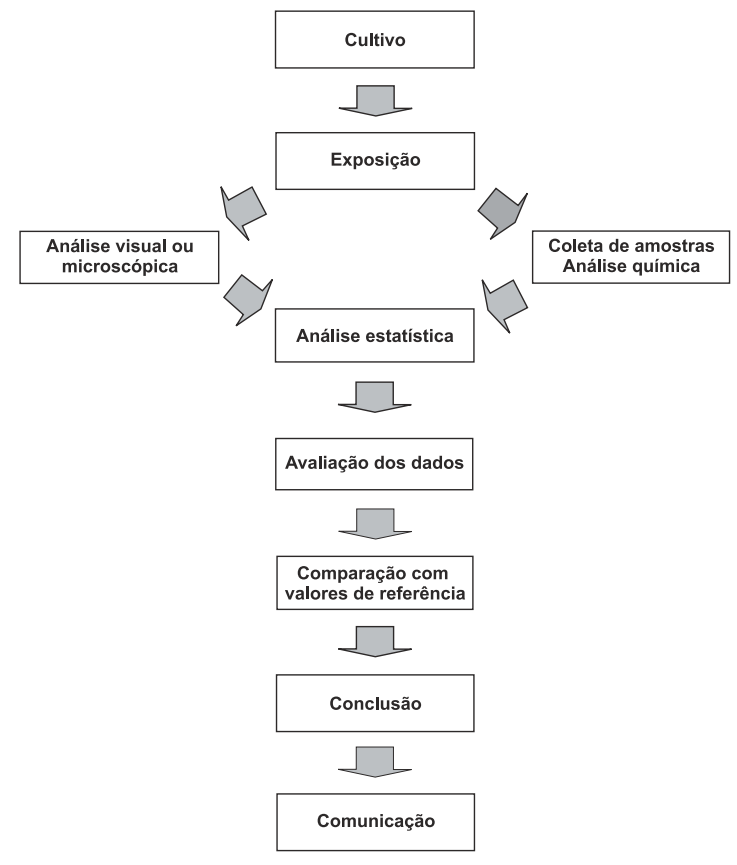

Figura 2. As etapas principais do uso de plantas bioindicadoras no monitoramento da qualidade do ar. 
de quem passa por lá. Mediante pequenos orifícios na parede do cubo, as pessoas podem olhar para dentro, satisfazendo muito mais sua curiosidade em relação às plantas do que se olharem as plantas expostas ao ar livre. Uma vez chamada a atenção para as plantas bioindicadoras instaladas dentro do cubo, o interesse do observador pode ser conscientemente conduzido ao projeto EuroBionet, através de painéis explicativos e, conseqüentemente, à questão da poluição ambiental. Os resultados da qualidade do ar em cada cidade é mostrado no cubo através de coluna contendo escala de 1 a 5 , que representa cinco classes crescentes de contaminação do ar, entre muito baixa e muito alta (EuroBionet 2000).

\section{Resultados}

Os primeiros resultados obtidos a partir da exposição de tabaco, no total de 81 sítios experimentais na rede de biomonitoramento européia, revelaram um gradiente de impacto de ozônio do norte para o centro e sul da Europa (figura 4). Enquanto o índice de danos em folhas de tabaco induzidos por ozônio foi bastante baixo nas cidades de Edimburgo (Escócia) e Copenhagen (Dinamarca), as plantas expostas na Itália, França, Áustria e no sul da Alemanha (Hohenheim, Ditzingen) mostraram danos graves a muito graves. Cidades no centro-norte da Europa, como por exemplo Düsseldorfe Sheffield, ficaram em uma posição intermediária.

As primeiras análises do conteúdo foliar de enxofre em L. multiflorum mostraram, em geral, baixa contaminação do ar por compostos de enxofre, com poucas exceções (figura 5). Considerando o pequeno número de dados disponíveis até o momento, esses resultados não devem ser generalizados.

A divulgação de dados atualizados, obtidos após as exposições periódicas de todas as espécies bioindicadoras nas diversas cidades, é constantemente efetuada através da página do projeto na Internet (EuroBionet 2000).
Quanto aos objetivos na área de comunicação, percebe-se, após o primeiro ano de atividades, que o conceito publicitário tem uma repercussão muito boa na mídia. O projeto tem tido amplo respaldo nos jornais e nas reportagens de emissoras de rádio e televisão regionais e nacionais. Apresentações públicas realizadas durante exibições e festivais ambientais, feiras comerciais e semanas de ciência foram a base para muitas publicações. A freqüência de visitantes no pavilhão EuroBionet ainda é difícil de ser estimada, somente podendo ocorrer através de números obtidos durante exibições públicas e visitas monitoradas. Primeiras estimativas na cidade de Lyon, por exemplo, indicaram um número de 10.000 visitantes no pavilhão durante os meses de julho a outubro de 2000.

\section{Perspectivas}

Como resultado do projeto espera-se, uma divulgação maior de métodos biológicos como o biomonitoramento com plantas para o controle da qualidade ambiental e um aumento da conscientização da população urbana para com problemas ambientais no seu próprio município. Pretende-se oferecer às repartições municipais um fundamento para a elaboração de planos de ação visando à melhoria da qualidade do ar e conseqüentemente da qualidade de vida, almejando-se que os municípios decidam estabelecer um programa rotineiro de biomonitoramento nas áreas urbanas, que seja mantido por meios próprios dos municípios ou por contratação de serviços de terceiros.

Perante a iminente definição de metas para uma política ambiental européia e a progressiva transferência de competências e responsabilidades

Tabela 2. Distribuição das tarefas entre a Universidade de Hohenheim e as equipes locais.

\begin{tabular}{ll}
\hline \multicolumn{1}{c}{ Universidade de Hohenheim } & \multicolumn{1}{c}{ Equipes locais } \\
\hline Coordenação geral & Coordenação local \\
Elaboração de métodos e distribuição de manuais & Instalação e manutenção da rede de biomonitoramento \\
Aquisição e distribuição de materiais & Cultivo das plantas bioindicadoras \\
Treinamento das equipes locais & Exposição das plantas bioindicadoras \\
Controle das metodologias aplicadas pelas equipes locais & Análise visual de danos e de crescimento (tabaco e choupo) \\
Cultivo e distribuição de Tradescantia & Coleta de amostras (azevém, couve) \\
Análises químicas e anatômicas & Dados climáticos e da poluição \\
Avaliação dos dados & Implementação do conceito de comunicação \\
Organização de reuniões e congressos & Publicidade \\
\hline
\end{tabular}




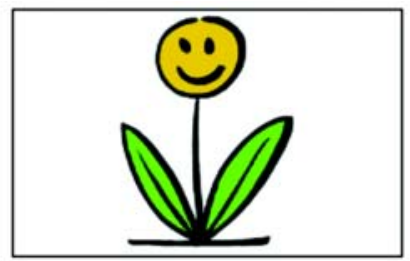

O herói

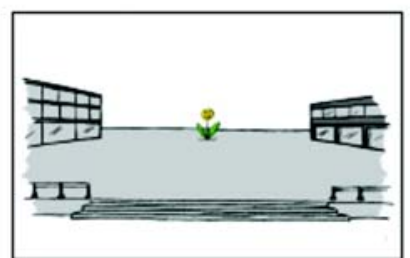

O problema

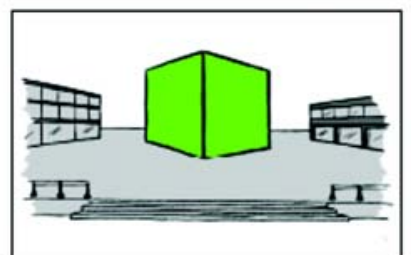

A idéia

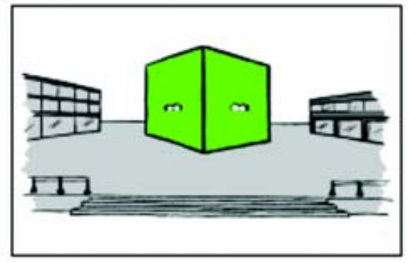

Criar curiosidade

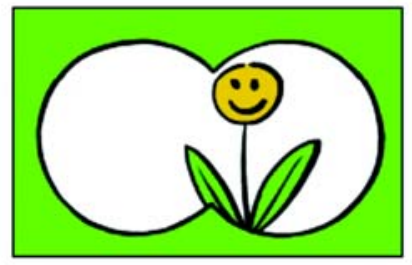

Satisfazer a curiosidade

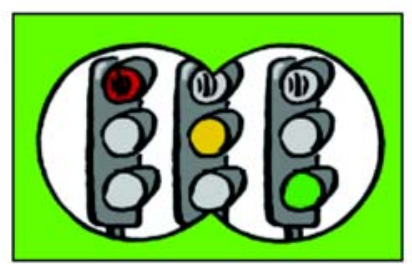

Entender como funciona

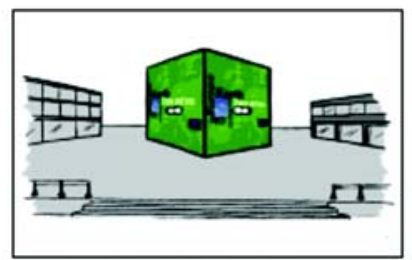

Compreender tudo

Figura 3. As idéias básicas da "experiência local”, o elemento central do conceito de comunicação do projeto EuroBionet. 


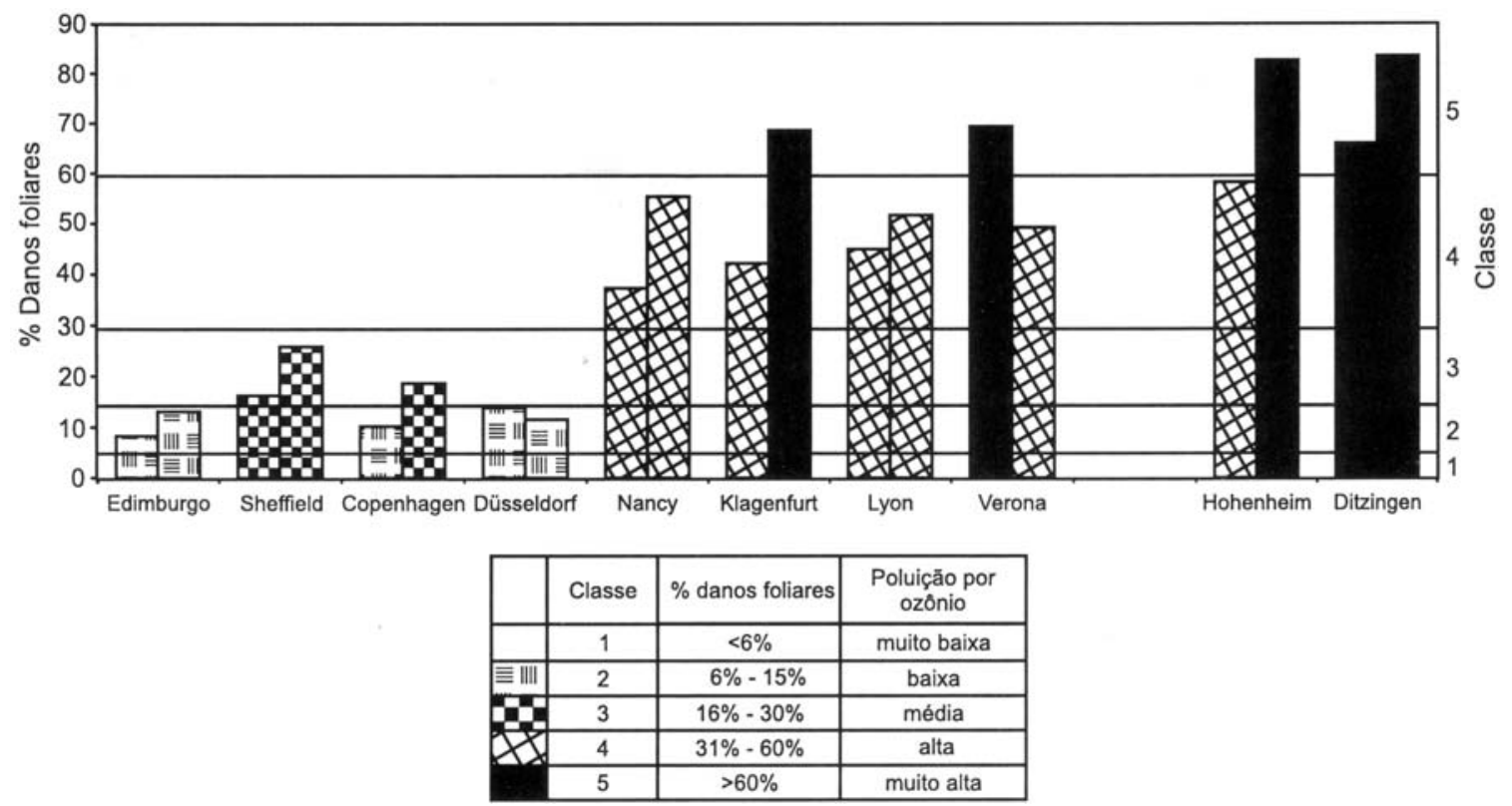

Figura 4. Resultados da exposição de tabaco em 81 sítios experimentais da rede de biomonitoramento realizada entre a $32^{\mathrm{a}} \mathrm{e}$ $34^{\mathrm{a}}$ (coluna à esquerda) e entre a $34^{\mathrm{a}}$ a $36^{\mathrm{a}}$ semanas do ano (coluna à direita), correspondentes a agosto/setembro de 2000. Classificação da poluição de acordo com MUN (1994).

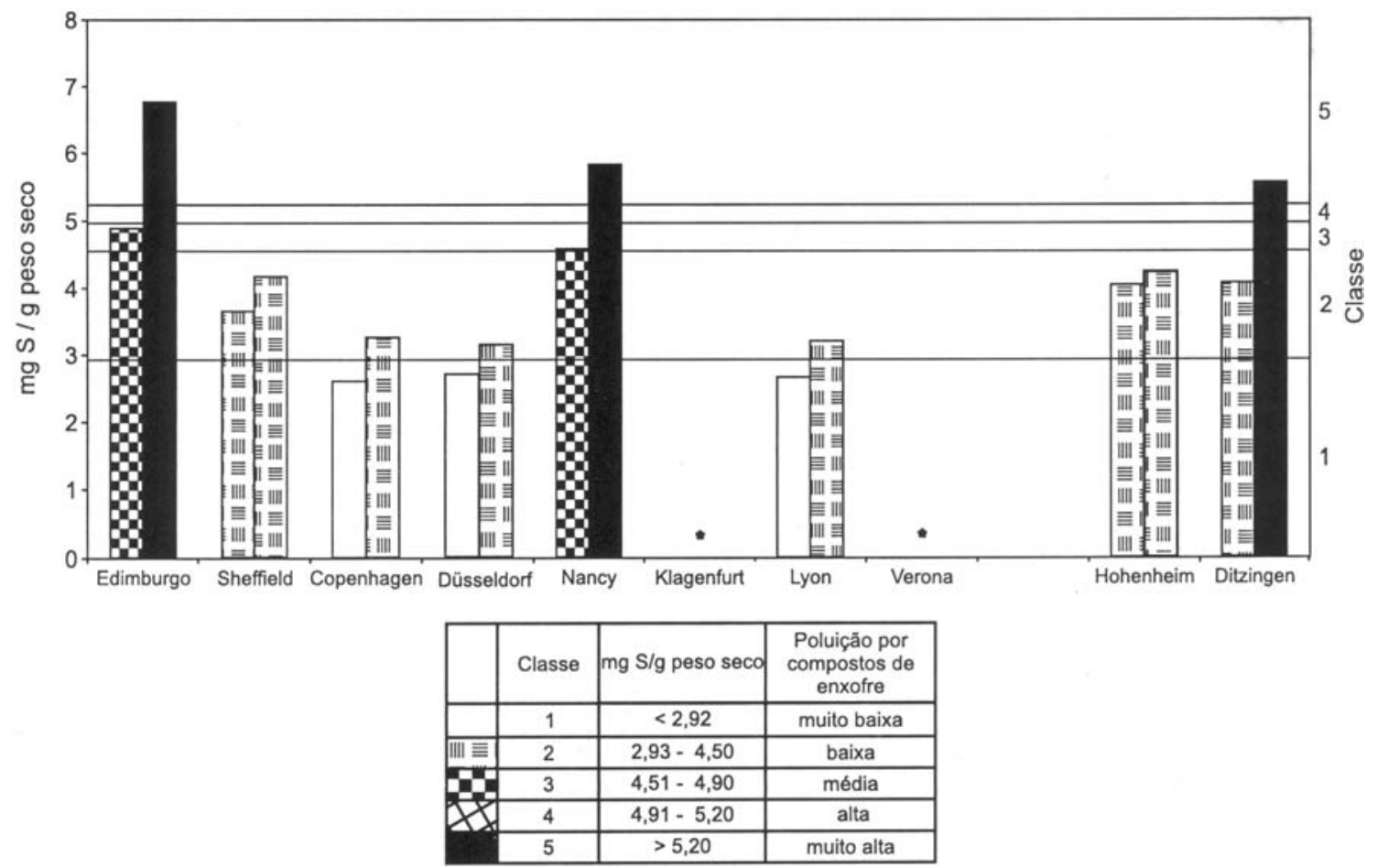

Figura 5. Resultados da exposição de azevém em 81 sítios experimentais da rede de biomonitoramento realizada entre a $28^{\mathrm{a}} \mathrm{e}$ $32^{a}$ semanas do ano (entre a $26^{a}$ e $32^{a}$ semanas, em Sheffield), correspondentes a julho/agosto de 2000. Coluna à esquerda: valor médio, coluna à direita: valor máximo, * dados não disponíveis. Classificação da poluição de acordo com MUN (1994). 
dos governos nacionais à União Européia, considera-se essencial que o projeto contribua para a padronização de métodos de biomonitoramento em nível europeu. Somente desta maneira haverá uma chance de se implantar, na futura legislação ambiental européia, metodologias que considerem os efeitos da poluição em plantas indicadoras com vistas ao estabelecimento de valores limites de concentração de poluentes no ar e legislação ambiental mais adequados.

Agradecimentos - Os autores agradecem à União Européia, Programa LIFE Environment, pelo apoio financeiro; às equipes locais de Barcelona, Copenhagen, Ditzingen, Düsseldorf, Edimburgo, Grande Lyon, Grande Nancy, Klagenfurt, Sheffield e Verona, pela cooperação na execução do projeto e aos técnicos da Universidade de Hohenheim, M. Alani, M. Beller, B. Meier, P. Schick e D. Wahnelt pela colaboração no cultivo de plantas, nas análises químicas e na administração do projeto.

\section{Referências bibliográficas}

ARNDT, U. \& SCHWEIZER, A. 1991. The use of bioindicators for environmental monitoring in tropical and subtropical countries. In Biological monitoring: signals from the environment (H. Ellenberg, ed.). Vieweg, Braunschweig, p.199-260.

ARNDT, U., ERHARDT, W., KEITEL, A., MICHENFELDER, K., NOBEL, W. \& SCHLÜTER, C. 1985. Verfahren zur standardisierten Exposition von pflanzlichen Bioindikatoren. Staub - Reinhaltung der Luft 45:481-483.

ARNDT, U., FLORES, F. \& WEINSTEIN, L. 1995. Efeitos do flúor sobre as plantas: diagnose de danos na vegetação do Brasil. Editora UFRGS, Porto Alegre.

BALLACH, H.J. 1997. Suitability and use of poplars as bioindicators. Environmental Science and Pollution Research 4:37-45.
EC - European Commission. 1998. LIFE in action. Demonstration projects for Europe's environment. Office for Official Publications of the European Communities, Luxemburgo.

EEA - European Environment Agency. 1998. Europe's environment: The second assessment. Elsevier, Oxford.

EUROBIONET. 2000. www.eurobionet.com

FOMIN, A., PRANG, L., HAFNER, C. \& ARNDT, U. 1995. Die Verwendung von Tradescantia als pflanzlicher Bioindikator für mutagene Wirkungen von Luftverunreinigungen. Umweltwissenschaften und Schadstoff - Forschung 7:293-298.

HEGGESTAD, H. E. 1991. Origin of Bel-W3, Bel-C and Bel-B tobacco varieties and their use as indicators of ozone. Environmental Pollution 74:264-291.

KLUMPP, A. 2001. Utilização de bioindicadores de poluição em condições temperadas e tropicais. In Indicadores ambientais - temas atuais (H.L. Martos, N.B. Mais \& W. Barrella, eds.). PUC São Paulo, São Paulo (no prelo).

MA, T.H., CABRERA, G.L., CHEN, R., GILL, B.S., SANDHU, S.S., VANDENBERG, A.L. \& SALAMONE, M.F.1994. Tradescantia micronucleus bioassay. Mutation Research 310:221-230.

MUN - Ministerium für Umwelt- und Naturschutz des Landes Sachsen - Anhalt. 1994. Luftreinhalteplan 1994 des Landes Sachsen - Anhalt. Untersuchungsgebiet 10: Hohenmölsen - Naumburg - Weißenfels - Zeitz. Band 2: Immissions - und Wirkungskataster. MUN, Magdeburg.

PEICHL, L. 1997. Landesweite Erhebung von Immissionswirkungen mit Bioindikatoren. Umweltwissenschaften und Schadstoff-Forschung 9:273-282.

VDI. 1978. Messen der Wirkdosis. Verfahren der standardisierten Graskultur. VDI 3792/1, Düsseldorf.

VDI. 1999. Biological measuring techniques for the determination and evaluation of effects of air pollutants on plants. Fundamentals and aims. VDI 3957/1. VDI/ DIN Handbuch Reinhaltung der Luft, v. 1a. Beuth, Berlin. VDI. 2000. Biological measuring techniques for the determination and evaluation of effects of air pollutants on plants. Standardised exposure of green cabbage. VDI 3957/3. VDI/DIN Handbuch Reinhaltung der Luft, v. 1a. Beuth, Berlin. 